\title{
Yurt Dışında Yaşayan İkinci Kuşak Türk Çocuklarının Türkçeyi Kullanım Durumları ve Dil-Kültür İlişkisi
}

İhsan Seyit Ertem*

\section{Özet}

Son yıllarda, Türk nüfusu tıpkı Avrupa'da olduğu gibi Amerika Birleşik Devletlerinde de azımsanmayacak derecede artmaktadır. Amerikan kültür ve dilinin güçlü baskısı özellikle ikinci kuşak çocuklarda ana dilleri olan Türkçenin ve Türk kültürünün zayıflamasına ve hatta yok olmasına neden olmaktadır. Bu çalışmada, Amerika Birleşik Devletlerinde yaşamakta olan özellikle ikinci kuşak Türk çocuklarının ana dilleri olan Türkçeyi kullanımı, aileleri ile olan iletişimleri ve kültürel unsurlar, çocukların yaşamakta oldukları dil ve kültür çatışmaları, ayrıca ailelerin kendi ana dillerini ve kültürlerini sürdürmek için neler yaptıkları incelenmiştir. Bu amaç doğrultusunda, nitel araştırma yöntemlerinden olan durum (örnek olay) incelemesi tekniği kullanılmıştır. Bir Türk ailesi ve 5 ve 11 yaşlarında olan çocukları ile olan iletişimleri, bu çocukların Türkçeyi kullanımları belli bir dönem gözlenmiş ve yazılı notlar alınmıştır. Elde edilen bulgular ve dokümanlar incelenmiş ve analiz edilmiş, ayrıca bulguları desteklemek için Türk aile ve çocukları ile ayrı ayrı mülakatlar yapılmıştır. Bu araştırmanın sonucunda; 1) ailelerin ana dillerini koruma ve sürdürme çabalarına rağmen ikinci kuşak Türk çocuklar arasında İngilizcenin yaygın olarak kullanıldığı; 2) ikinci kuşak çocukların kültürel uyum sorunu çektiği, dil ve kültür çatışması yaşadıkları; 3) aile ile çocuklar arasında kültürel uyuşmazlıkların olduğu; 4) eğitim kurumlarının dil ve kültür aktarımında belirleyici bir faktör olduğu sonuçlarına ulaşılmıştır.

Anahtar Kelimeler: Yurt dışında yaşayan ikinci kuşak Türk çocukları, ana dil, Türk kültürü, kültürel çatışma

Case of Using Turkish Language of Second-Generation Turkish Children Living Abroad and Relationship Between Language-Culture

\begin{abstract}
In recent years, Turkish population in the United States as in Europe has increased substantially. Strong pressures from the American culture and language have commonly led to weakening and even the extinction of
\end{abstract}

*Yrd. Doç. Dr., Gazi Üniversitesi, Eğitim Fakültesi, Sınıf Öğretmenliği Eğitimi 
Turkish language and culture especially in the second generation of children with native language is Turkish. In this study, use of Turkish language of second-generation Turkish children living in the United States, communications with their families and cultural elements in those communications, their language and cultural conflicts, as well as their families do to maintain their native language and culture were examined. For this purpose, the case study method was used in qualitative research methods. Communications between a Turkish family and their 5 and 11 years old children were being observed in a certain period of time and the written notes were taken. Unstructured interviews were conducted with Turkish family and children and documents were also examined to support the findings. Results of the study indicate that: 1) Despite the efforts of families to maintain and protect the native language, English is widely used among second-generation Turkish children, 2) the second generation of children have the problem of acculturation and language and culture conflict, 3) the cultural inconsistency between family and children; 4) educational institutions are the determining factor in the transmission of language and culture.

Keywords: Second-generation Turkish children living abroad, native language,Turkish culture, cultural conflict

\section{Giriş}

1960'lı yıllardan itibaren, başta Almanya olmak üzere çeşitli Avrupa ülkelerinde çalışmak maksadıyla çok sayıda Türk vatandaşı yurtdışına gitmiştir.1960'lı yıllarda başlayan iş göçü, ilerleyen yıllarda değişik vesilelerle daha da artmış ve bu sayının son zamanlarda 4 milyona yaklaştı̆̆1 varsayılmaktadır. 2000 yılı Amerika Genel Nüfus sayımı rakamlarına göre ülkede yaşayan toplam Türk sayısı 117.575 olarak belirlenmiştir. Son yıllarda ise Amerika genelinde 250-300 bin civarında birinci ve ikinci kuşak Türk nüfusu olduğu, diğer Türk asıllı soydaşlarla birlikte bu rakamın 500.000 dolayında olduğu tahminleri yapılmaktadır. (Yavuzer, 2009). Türk vatandaşlarının yurt dişına göç etmeleri sonucu göç olgusunun doğası gereği de olarak bir takım sorunları da beraberinde getirmiştir. Bu sorunlardan en belirgin olanları ki bu araştırmaya kaynaklık etmektedir; ana dilin kullanımı ve kültür çatışmalarıdır.

Nesiller arası kültürel sürekliliğin, kültürel bilgi ve değer aktarımının en önemli aracı dildir. Bu aracın yeni nesillere aktarılamaması veya sağlıklı bir şekilde nesiller arasında kullanılamaması kültürel süreklilik peşindeki aileleri zor durumda bırakmaktadır. Elbette yabancı bir ülkede 
yaşamaya karar vermiş kişilerin bulundukları ülkenin dilini ve kültürünü hiçbir şekilde öğrenmeden o ülkede yaşamayı sürdürmeleri beklenemez ancak kendi dillerini ve kültürlerini tamamen terk etmeye zorlanmaları da kabul edilmez bir durumdur. Yurt dışında yaşayan vatandaşlarımızın hem yaşadıkları ülkenin dilini öğrenmede hem de geldikleri ülkenin dilini çocuklarına öğretmede ciddi sorunlar yaşadıkları görülmektedir. Bu durum aile içi ilişkilerden çocukların eğitimine, iş hayatından toplumla ilişkilere kadar birçok alanda soruna neden olmaktadır (Nuruan ve diğerleri, 2005).

Amerika Birleşik Devletlerinde yaşayan göçmenler ana dillerini ve kültürlerini korumada ve sürdürmede güçlükler yaşamaktadır. Genel olarak, aileler çocuklarının iyi derecede İngilizce öğrenmelerini ve Amerikan kültürüne uyum sağlamlarını isterken; öte yandan, kendi ana dillerini ve kültürlerini de korumalarını beklemektedir. Mevcut durum bunun tam aksine çocukların İngilizceleri gelişirken akıcı bir şekilde ana dillerini konuşmaları gerilemektedir. Dil bilimciler, ana dil ve kültürü korumanın kişisel bir sorun olmanın yanında sosyal bir sorun olduğuna da vurgu yapmaktadır. $\mathrm{Bu}$ nedenle, ana dili korumayı engelleyen faktörlerin ve şartların iyi anlaşılması gereklidir. Dil, sosyal bir kurum olarak toplum tarafından biçimlendirilir ve topluma yön verir. Dilin kültürle olan ilişkisine kültürün uygulaması olarak bakılabilir ve dil ile kültür arasında etkileşim vardır. Çünkü dil bağımsız bir yapıdan öte içinde yaşadığımız toplumsal yapı ve kurumları etkileyen bir olgudur (Fairclough, 1989).

\section{Dil ve Kültür}

Birçok araştırmacı dil ve kültür arasındaki bağlantı üzerine yorumlar yapmıştır ancak araştırmacılar arasında görüş birliği olduğu söylenemez. Portes ve Schauffler (1994:641) "Kültür karmaşık yapısıyla, normlar, değerler, inançlar, dil ve geleneklerin yanında bireylerin toplumun bir üyesi olarak toplum tarafında verilen veya öğrenilen beceri ve alışkanlıkları da içeren sembolik sistemler bütünüdür" şeklinde bir tanımlama yaparken kültürün dili de içine alan kapsamlı bir yapı olduğu vurgulamaktadır. Ayrıca, ana dilin sosyal rolüne işaret etmiş, ana dili konuşmanın sosyal hareketin bir biçimi olduğunu, insanların anlam üzerinde uzlaşmasını temsil ettiğini ve dil ve içeriğin karşılıklı olarak birbirini etkilediğini vurgulamıştır. Bunun sonucu olarak dil öğrenmenin sadece zihinsel değil aynı zamanda sosyal bir süreç olduğuna değinmiştir. Portes ve Schauffler'in görüşlerine paralel olarak Salzman (1998) dilin, kültürel bir ortam içerisinde grup kimliğinin kuşaktan kuşağa aktarılmasında ve kültürün içselleştirilmesinde önemli rol oynadığ 
üzerinde durmuştur. Diğer taraftan, kültürel kimliği sahiplenmek için dile hâkimiyetin gerekli olmadığını, Amerika Birleşik Devletlerinde ana dilini çok az konuşabilen ya da hiç konuşamayan birçok ikinci kuşak göçmenin kendisini geldiği ülkenin kimliği ile nitelendirdiğini savunan araştırmacılarda bulunmaktadır (Henle, 1970). Bu tartışmadan anlaşılacağ 1 üzere kültürel kimlik ve ana dil arasındaki ilişki çok net olmadığ 1 yönündedir. İkinci kuşak göçmen çocuklarının kendilerini ailelerinin kültürel kimliğine mi yoksa göç edilen ülkenin kimliğine mi ait oldukları tartışma konusudur.

Bazı araştırmacılar dil ve kültür arasındaki ilişkinin ayrılamaz biçimde bağlantılı olduğunu kanıtlamaya çalışmışlardır (Ochs-Schieffelin, 1994; Poyatos, 1985; Peters-Boggs, 1986). Gerekçe olarak: 1) dil öğreniminin evrensel bir sıra izlememesini ve kültürler arası farklılık göstermesini; 2) bireyin toplumun başarılı bir üyesi olmasının dilin belli sosyal durumlarda etkin kullanımına bağlı olmasını; 3) her toplumun çocukların sosyal durumlara katılımını koordine etmesini, bu durumunda çocukların konuşma biçim, fonksiyon ve içeriğini belirlemesini gösterdiler.

Kültür ve iletişim ayrılamaz çünkü kültür, iletişim sürecini belirler, ayrıca insanların mesajları nasıl kodlayacaklarını, mesajların anlamlarını ve hangi durumlarda farklı mesajların gönderilip gönderilmeyeceğini veya yorumlanmasını belirler. Dilin yapısal özellikleri ve gramer kategorisi konuşmacının çevresini nasıl kavramsallaştırdığını belirler. Kültürün gramer yapısı insanların davranış tarzı üzerinde etkilidir ve kültürler arasında kavramsal organizasyon farklılık gösterir (Howell-Vetter, 1976).

Vygotsky (1962), sosyal çevrenin öğrenme süreci üzerin etkisini araştırdı ve kültürün bilginin yapılandırılmasında temel belirleyici unsur olduğunu savundu. Öğrencinin akranları, öğretmeni ve diğer yetişkinlerle etkileşimi sonucu öğrenme gerçekleşmektedir. Öğretmenlerin temel görevi bireyin öğrenme yeteneğini en üst düzeye çıkarabilmesi için birbirleriyle etkileşim kurabileceği tartışma, işbirliği ve geribildirim gibi öğrenme ortamlarını düzenlemektir. Ayrıca, Vygotsky (1962), başkalarıyla etkileşimin kültürel mercek aracılığıyla gerçekleştiğini ve kuralların, becerilerin ve yeteneklerin kültür tarafından biçimlendirildiğini belirtmiştir. Kültürün ve sosyal çevrenin öğrenme üzerine etkisinin yanı sıra, Vygotsky (1978), dilin düşünme gelişimine, nedenselliğe, okuma ve yazma üzerine önemli katkıda bulunduğunu vurgular. Vygotsky'nin görüşleri, dil öğreniminin sosyal ortamdan ayrı düşünülemeyeceğini, öğrencilerin birbiriyle veya yetişkinlerin çocuklarla güncel konular üzerine tartışmaları, işbirliği yapmalarının dil gelişimine sayısız katkı sağladığı ve çocukların dil, 
beceri ve deneyimlerinin bu sosyal ortam içerisinde kültür tarafından biçimlendirildiği şeklinde ifade edilebilir. Vygotsky'nin teorisi ve Bruner'in gelişim teorisi birbirine paralel olarak sosyal etkileşimin dil üzerindeki etkisini vurgulamaktadır. Özet olarak Vygotsky'ye göre:

- Zihinsel gelişimde en önemli unsur sosyo-kültürel çevredir

- Farklı sosyal ortamlar farklı gelişim biçimleri yaratır

- Zihinsel süreçler (dil, düşünce ve nedensellik) sosyal etkileşim sayesinde gelişir

- Gelişme kültürün ürünüdür (1978).

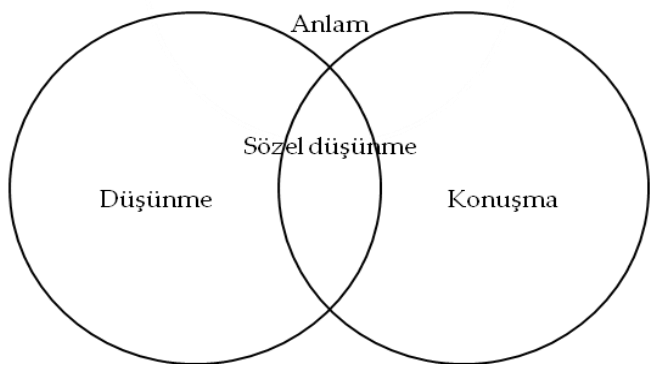

Şekil 1: Vygotsky'nin Dil Gelişimi ve Düşünme Teorisi (Wink \& Putney, 2002)

Şekil 1 Vygotsky'nin düşünme, konuşma ve sözel düşünmenin gelişimi arasındaki bağlantıyı açıklayan teorisini kısaca göstermektedir. Konuşma burada düşüncenin aktarıldığı bir aracı işlevi görmektedir tıpkı diğer soyut semboller sitemi gibi örneğin: sayılar, yazı, resim vb. Vygotsky (1978) bireylerin dil öğreniminde sosyal etkileşimin özellikle geçiş ve içselleştirme süreçlerinde önemli rol oynadığını savunur. Dil gelişimi ilk olarak sosyal alanda daha sonra ise bireysel alanda gerçekleşir. Çocuk ailesinin davranışlarını gözler, konuşmalarını dinler ve onları taklit etmeye çalışır. Ailelerde çocuğun bu çabasına rehberlik eder, düzeltmeler yapar ve ihtiyaç duyduğunda uygun ipuçları sunar. Çocuk dil açısından daha yeterli hale geldiğinde içselleştirir ve artık dil içsel konuşma veya zihinde düşünce olarak temsil edilir. Bakthin kelimelerin kişinin kendi anlamsal ve açıklayıcı amacına uygun olarak adapte edildiği ve kullanıldığı sürece içselleştiğini ifade eder (Holquist, 1990). Dil öğrenimi konusundaki bu teorik bilgiler, 
ikinci kuşak Türk çocuklarının ana dillerini öğrenme ve kullanmaları konusunda açıklayıcı olacaktır.

\section{Araştırmanın Amacı ve Yöntem}

$\mathrm{Bu}$ araştırmada üç temel amacı bulunmaktadır. Birincisi, Amerika Birleşik Devletlerinde yaşayan ikinci kuşak Türk çocuklarının kültürel kimlik ve dil tercihleri arasındaki ilişkiyi; ikinci olarak bu çocukların Türkçeyi nasıl kullandıklarını ve son olarak da aileleri ile olan iletişimlerini ve bu iletişimde yer alan kültürel unsurları incelemektir.

$\mathrm{Bu}$ amaç doğrultusunda nitel araştırma yöntemlerinden durum (örnek olay) incelemesi tekniği kullanılmıştır. Durum (örnek olay) incelemesi, her aşaması dikkatli bir biçimde desenlenmesi gereken, sağlam gerekçelere dayandırılması ve teknik araştırma bilgisi gerektiren bir tekniktir (Yıldırım-Şimşek, 2011: 280). Durum araştırmalarında, araştırma konusu ayrıntılı ve derinlemesine incelenir. Araştırmacı kimleri araştırmaya dahil edeceğine karar verir, veri toplama zamanını belirler. Bütün bu aşamalarda araştırma problemiyle ilgili alan yazın etkili bir şekilde kullanılır. Bu araştırmada amaçlı örneklem yöntemiyle belirlenen, Amerika Birleşik Devletleri'nin Florida eyaletine 13 yıl önce göç etmiş olan bir Türk ailesi ve 5 ve 11 yaşlarındaki çocukları ile olan iletişimleri, çocukların Türkçeyi kullanımları iki ay süresince katılımcı gözlem yöntemi ile gözlenmiş ve notlar alınmıştır. Durum araştırmacısı verisini toplarken mümkün olduğu ölçüde birden fazla veri kaynağı ve türünü kullanmalıdır (Yıldırım-Şimşek, 2011). Bu amaçla, elde edilen bulgular ve dokümanlar incelenmiş, bulguları desteklemek ve veri çeşitlemesinin sağlanması için Türk aile ve çocukları ile yapılandırılmamış mülakatlar gerçekleştirilmiştir.

Verilerin analizi ise betimsel analiz yaklaşımı izlenerek, belirlenen temalara göre özetlenip yorumlanmıştır (Yıldırım-Şimşek, 2011).Veri analizi dört aşamadan oluşmuştur: 1) Betimsel analiz için bir çerçeve oluşturulması 2) tematik çerçeveye göre veriler işlenmesi 3) bulguların tanımlanması 4) bulguların yorumlanması.

\section{Bulgu ve Sonuçlar}

İkinci kuşak Türk çocuklarının dil çatışması yaşadıkları ve ana dillerinin akıcılığını kaybettikleri gözlenmiştir. Burada okul ve sosyokültürel çevrenin etkisi açıkça görülmektedir. Okul İngilizce dışında materyal ve ortam sunmamaktadır. Kalış süresi ve Türk nüfusun bölgedeki yoğunluğu ana dilin kalıcılığı üzerinde etkili olan faktörlerdir. Kalış 
süresinin uzaması ve Türk nüfusun yoğun olmadığı bölgelerde ana dil kaybı daha kısa sürede gerçekleşmektedir.

Yurt dışına göç eden ailelerde kuşaklar arası ana dil gelişiminin izlediği genel süreç şu şekildedir: Birinci kuşak aileler hayatını sürdürebilmek için İngilizceyi öğreniyor, ikinci kuşak çocuklar sadece evde ana dil konuşuyor, okulda ve diğer sosyal yaşamlarında İngilizceyi tercih ediyor; üçüncü kuşak ailelerde ise evde konuşulan dil tamamen İngilizceye dönüşüyor.

$\mathrm{Bu}$ araştırma kapsamında yer alan Türk aile evde Türkçe konuşulduğu takdirde çocuklarının ana dillerini unutmayacağını düşünmektedir. Aile, çocuklarına Türkçe ve Türk kültürünü yeterince verildiği sürece çocuklarının Amerikan toplumu tarafından asimile edilemeyeceğine inanmaktadır. İkinci kuşak Türk çocuklarında ana dil olan Türkçenin işlevi sadece konuşma ile sınırlıdır, araştırma esnasında, Türkçe okuma ve yazma faaliyetleri gözlenmemiştir.

Aile çocuklarının akademik ve mesleki başarıları için çocuklarının İngilizce öğrenmesini teşvik etmektedir. Küçük yaşlarda televizyon ve çizgi filmler, arkadaşları ve okul öncesi kurumlar (preschool) etkili olurken daha sonra ilkokul (elementary school) ve sosyal çevre baskın faktör olarak görülmektedir.

Amerika Birleşik Devletlerinde ikinci kuşak Türk çocukları, aile içerisinde geçirilen zamanın azalması ile doğru orantılı olarak; yaşları büyüdükçe iletişimde yoğun olarak İngilizceyi tercih etmektedirler. Bunun sonucu olarak çocuklar zaman ilerledikçe kendilerini yabancı kültüre daha yakın hissettikleri görülmektedir.

Birinci kuşak Türk aile, kültürel değerlerini ve ana dilini muhafaza etmektedir. Bu durum aile içi iletişimde ve ikinci kuşak Türk çocuklarının dil gelişiminde etkili olmaktadır. Bakhtin, dil öğreniminde kelimeleri anlamlandırmanın içsel söylemlerle otorite söylemlerin karşılaştırılması sonucu oluştuğunu savunur. Bu karşılaştırmanın dönüm noktası otorite söylemlerin (anne-babanın kelimeleri) sonunda içsel söyleme (çocuğun kendi kelimeleri) dönüşmesidir. Bir başka deyişle, kelimelerin bireysel anlamlandırılması anne ve babanın katkısıyla bağlam içersinde nihai biçimine veya söyleme dönüşür (Holquist, 1990). Bu araştırmada sık sık gözlenen, özellikle annenin çocukların Türkçe konuşmalarında yapmış oldukları telaffuz hatalarına veya kelimelerin yanlış kullanımına yönelik düzeltmeler bu teorik çerçeve içerisinde düşünülebilir. Çocuklar, yetişkinlerin Türkçe konuşmalarına sıklıkla katılmaktadır. Konuşma 
içerisinde duydukları kısa Türkçe kelimelerin sesli olarak zaman zaman tekrar edilmesi, şarkı nakaratlarının öğrenilmesi ve tekrarı, sentakstan (söz dizimi) önce kelime telaffuzlarının öğrenildiğini ve kullanıldığını göstermektedir.

İkinci kuşak çocuklar tarafından Türkçenin kullanımına ilişkin diğer bir bulgu ise konuşmalarda emir cümlelerinde özne atılarak, emir cümlesinin tonlamasına uygun şekilde çok sık kullanılıyor olmasıdır. Örneğin: "yerine koy, buraya gel, burada gibi. Çocuklarda kelime bilgisi özellikle zıtlık belirten kelimeler, sayılar, zamanla ilgili kavramlar yetişkinler düzeyindedir ve içeriğe uygun olarak kullanılmaktadır. Karmaşık ve bileşik cümlelerle ilgili yönergeleri anlıyor olmalarına rağmen çocuklar konuşmalarında bu cümleleri kullanmadıkları gözlenmiştir.

Türk aile üyeleri ile yapılan görüşmeler sonucunda ortaya çıkan bir diğer bulgu ise, evde Türkçe tercih edildiği takdirde çocuklarının okuldaki akademik başarılarının düşeceği endişesi taşıdıkları yönündedir. Ancak yapılan çalışmalar bu endişelerin yersiz olduğunu göstermektedir. Örneğin, Amerika Birleşik Devletleri ülke genelinde lise öğrencileri üzerinde yapılan bir araştırmada hem ana diline aynı zamanda İngilizceye hakim olan öğrencilerin akademik başarısında herhangi bir düşme olmadığı gibi aksine pozitif bir etki yarattığı görülmüştür, bir başka araştırmada öğrencilerin İngilizce okuma becerileri ile çift dil bilmeleri arasında herhangi bir ilişki bulunamamıştır (Portes ve Schauffler, 1994). Ailenin bir diğer endişesi ise çocukları İngilizceye yeteri kadar hakim olmadıkları sürece hem devlet kurumlarında ve aynı zamanda toplumsal olarak ön yargıya maruz kalacakları ve dezavantajlı duruma düşecekleri şeklindedir. Daha önce açıklandığı üzere bu durum anadilini korumak isteyen Türk ailenin istekleri ve endişeleri arasında bir ikilem yaşadıklarının açık göstergesidir.

Araştırma sonucu göstermiştir ki ikinci kuşak çocuklarında ana dilin korunması ve geliştirilmesi eğitimsel ve kültürel kaynaklara bağlıdır. Eğitimsel kaynak olarak Milli Eğitim Bakanlığı tarafından özellikle ikinci kuşak Türk çocuklarının yoğun olarak devam ettikleri okullarda Türkçe dersinin verilmesi, öğrencilerin gerekli kaynak ve materyallerle desteklenmesi düşünülebilir. Yurt dışında yaşayan Türk ailelerin birbirleriyle irtibatını koruyarak ve kültürel aktivitelere katılarak ana dilin gelecek nesillere aktarılmasının sağlanmasıdır. Amerikan hükümetinin korkularının aksine göçmen aileler hızlı bir şekilde ana dillerini kaybetmektedirler. Eğitimli ve bilinçli aileler dahi bu değişime karşı koyamamaktadir. 


\section{Kaynakça}

Bruner, J. (1990). Acts of Meaning, Harvard University Press: Cambridge.

Bruner, J. (1996). The Culture of Education, Harvard University Press: Cambridge.

Damen, L. (1987). Culture Learning: The Fifth Dimension in the Language Classroom, Addison-Wesley: Reading.

Fairclough, N. (1989). Language and Power, Longman: London.

Fairclough, N. (1995). Critical Discourse Analysis, Longman: London.

Henle, P. (1970). Language, Thought and Culture, Michigan University Press: Michigan.

Holquist, M. (1990). Dialogism: Bakhtin and His World, Routledge: London.

Howell, W., R. \& Vetter, J., H. (1976). Language in Behaviour, Human Sciences

Press: New York.

Landar, H. 1965. Language and Culture, Oxford University Press: USA.

Nuruan, M., Güneş, T., Şen, R., B., Güneş, S., Kalaycı, A., R. \& Kaplan, M. (2005). Federal Almanya'da Yaşayan Türklerin Aile Yapısı ve Sorunları Araştırması, Aile ve Sosyal Araştırmalar Genel Müdürlüğü: Ankara.

Ochs, E., \& Schieffelin, B. (1984). Language Acquisition and Socialization. In R. Shweper \& R. Levine (Eds.), Culture theory (pp. 277-320). Oxford University Press: Oxford.

Peck, D. (1998). Teaching Culture: Beyond Language, New Haven Teachers Institute: Yale.

Peters, A., \& Boggs, S. (1986). Interactional Routines as Cultural Influences Upon Language Acquisition. B. Schieffelin and E. Ochs (Eds.), Language socialization across cultures (pp. 80-96). Cambridge University Press: Cambridge.

Portes, A. \& Schauffler, R. (1994). "Language and the Second Generation: Bilingualism Yesterday and Today", International Migration Review, 28 (4), 640-661.

Poyatos, F. (1985). Encoding-decoding Processes in Verbal and Nonverbal Interaction. In R. Brunt \& W. Enninger (Eds.), Interdisciplinary perspectives at cross-cultural communication (pp. 191- 210). Rader: Achen. 
Uşak Üniversitesi Sosyal Bilimler Dergisi

Salzmann, Z. (1998). Language, Culture and Society: An Introduction to Linguistic Anthropology, Westview Press: USA.

Steele, R. (1989). Teaching Language and Culture: Old Problems and New Approaches. In J.E. Alatis (Ed.), Georgetown University roundtable on languages and linguistics (pp. 153-162). Georgetown University Press: Washington.

Vygotsky, L.,S. (1962). Thought and Language. (E. Hanfmann \& G. Vakar, Trans. \& Eds.). MIT Press: Cambridge.

Vygotsky, L., S. (1978). Mind and Society: The Development of Higher Psychological Process, M. Cole, V. John-Steiner, S. Scribner, \& E. Souberman (Eds.), Harvard University Press: Cambridge.

Wells, G. (Ed.). (1981). Learning Through Interaction: The Study of Language Development, Cambridge University Press: Cambridge.

Wink, J., \& Putney, L. (2002). A vision of Vygotsky. Allyn \& Bacon: Boston.

Yavuzer, H. (2009). “Amerika' daki Türkler ve Kurmuş Oldukları Türk Dernekleri", Zeitschrift für die Welt der Türken/ Journal of World of Turks, 1(1), 171-198.

Yıldırım, A. \& Şimşek, H. (2011). Sosyal Bilimlerde Nitel Araştırma Yöntemleri, Seçkin Yayıncılık: Ankara. 